\title{
Design, Fabrication, and Characterization of High Temperature Joints in Ceramic Composites
}

\author{
M. Singh \\ FDC-NYMA, MS 106-5 \\ NASA Lewis Research Center Group \\ Cleveland, $\mathrm{OH} 44135$ (USA)
}

Keywords: Design, Fabrication, Testing, Joints, Ceramics, Composites

\begin{abstract}
Ceramic joining has been recognized as one of the enabling technologies for the successful utilization of ceramic components in a number of demanding, high temperature applications. Various joint design philosophies and design issues have been discussed along with an affordable, robust ceramic joining technology (ARCJoinT). A wide variety of silicon carbide-based composite materials, in different shapes and sizes, have been joined using this technology. This technique is capable of producing joints with tailorable thickness and composition. The room and high temperature mechanical properties and fractography of ceramic joints have been reported. These joints maintain their mechanical strength up to $1200^{\circ} \mathrm{C}$ in air. This technology is suitable for the joining of large and complex shaped ceramic composite components and with certain modifications, can be applied to repair of ceramic components damaged in service.
\end{abstract}

\section{Introduction}

Ceramic composites are either currently being used or are under active consideration for use in a wide variety of high temperature applications within the aeronautics, energy, process, nuclear, and transportation industries. Silicon carbide-based ceramics and fiber reinforced composites are being developed for engine components, radiant heater tubes, heat exchangers, heat recuperators, and components for land based power generation turbines. The engineering designs require fabrication and manufacturing of complex shaped parts which are quite expensive. In many instances, it is more economical to build up complex shapes by joining together simple geometrical shapes. Thus, joining has been recognized as one of the enabling technologies for successful utilization of silicon carbide-based ceramic and fiber reinforced composite components in high temperature applications. However, the joints must retain their structural integrity at high temperatures and must have mechanical strength and environmental stability comparable to the bulk materials. In addition, the joining technique should be robust, practical, and reliable.

Overviews of various joining techniques for ceramics, e.g., mechanical fastening, adhesive bonding, welding, brazing, and soldering have been provided in various publications [1-8]. The majority of the techniques used today are based on the joining of monolithic ceramics and fiber reinforced composites with metals and ceramics either by diffusion bonding, metal brazing, brazing with oxides and oxynitrides, or diffusion welding. Some of these techniques require either high temperatures for processing or hot pressing. In other instances, the joint use temperatures are lower than the temperature capability of the base ceramics or composites. The joints produced by brazing techniques can have different thermal expansion coefficients than the parent materials, which contributes to stress concentration in the joint area. Normally, the use temperatures for brazed joints are limited to $-700{ }^{\circ} \mathrm{C}$.

Ceramic joint interlayers have been developed as a means of obtaining high temperature joints. These joint interlayers have been produced via pre-ceramic polymers, in-situ displacement reactions, and tape casting/reaction bonding techniques [8-10]. Joints produced by the pre-ceramic polymer approach exhibit significant amounts of porosity, low crystallinity, and poor mechanical properties. On the other hand, hot pressing or high temperature fixtures are needed for in-situ displacement reactions, diffusion bonding, and tape casting-reaction bonding techniques [9]. Due to the equipment required, these techniques are not well suited for joining large or complex shaped components.

Various joint design philosophies and design issues are discussed in this paper, along with an affordable, robust ceramic joining technology (ARCJoinT). ARCJoinT, which is based on the reaction forming approach, is unique in terms of producing joints with tailorable microstructures. The formation of joints by this approach is attractive since the thermomechanical properties 
of the joint interlayer can be tailored to be very close to those of the silicon carbide base materials. In addition, high temperature fixturing is not needed to hold the parts at the infiltration temperature. A variety of silicon carbide-based ceramics and fiber reinforced composites have been joined using this approach [11-17]. The room and high temperature flexural strength and fractography of ceramic joints are reported.

\section{Joint Design Issues}

Numerous joint design and testing activities in the past have been related to metal-metal and ceramic-metal systems. For ceramicmetal systems, various joint designs and design criteria have been established $[3,8]$. The designs accommodate a number of factors including stresses and stress distribution in the joint regions, which are dependent upon joint configuration and chemical and thermal properties mismatch between the joint and substrate materials. Determination of the mechanical properties of the joint is critical to designers. A wide variety of testing methods $[3,8]$ have been used to determine the tensile strength, peel strength, flexural strength, shear strength, and compressive strength of the ceramic-metal joints. However, unlike the joining technology for ceramicmetal systems, joint design and testing is not well developed for ceramic-ceramic systems. If the ceramic materials have to be used at high temperatures under extreme operating conditions, a number of joint design issues have to be considered along with high temperature thermal and environmental stability of the joint and the joint-substrate interface. One such design and testing issue is the determination of the stress state at the joint, namely, tensile, shear, or a combination of tensile and shear stresses under operating conditions. In addition, the design of joints must take into account the response of joints to temperature changes.

\section{Fabrication}

A flow diagram of the affordable, robust ceramic joining technology (ARCJoinT) is given in Fig. 1. The joining process begins with the application of a carbonaceous mixture in the joint area, holding the items to be joined in a fixture, and curing at $110-120^{\circ} \mathrm{C}$ for 10 to 20 minutes. This step fastens the pieces together. Then, silicon or a silicon-alloy in tape, paste, or slurry form is applied around the joint region and heated to $1250-1425^{\circ} \mathrm{C}$ (depending on the type of infiltrant) for 10-15 minutes. The molten silicon or silicon- refractory metal alloy reacts with carbon to form silicon carbide with controllable amounts of silicon and other phases as determined by the alloy composition. Joint thickness can be readily controlled in this process by controlling the properties of the carbonaceous paste and applied fixturing force.

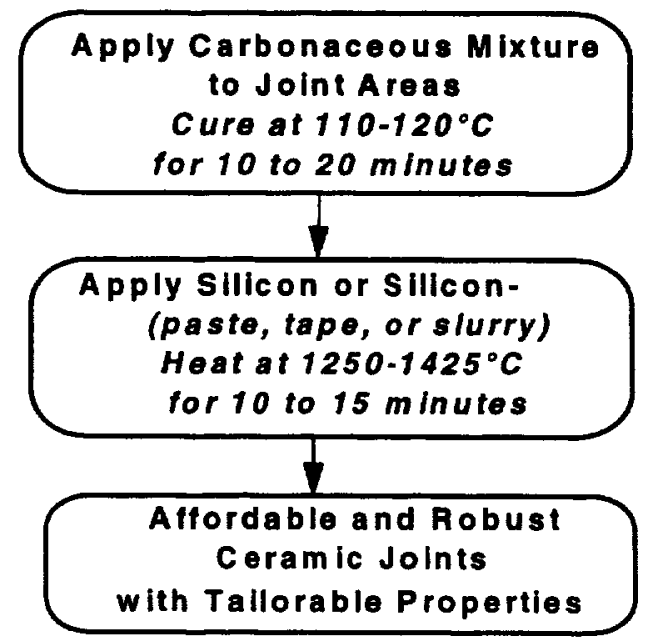

Fig. 1: Schematic of ARCJoinT process for joining silicon carbide-based materials.

A wide variety of silicon carbide-based ceramics and ceramic matrix composites, consisting of different sizes and shapes, have been joined using this technology. They include reaction-bonded silicon carbide ( $\mathrm{SiC}+\mathrm{Si})$, reaction-formed silicon carbide $(\mathrm{SiC}+\mathrm{Si})$, and sintered silicon carbide. Microstructural characterization and mechanical properties of joints in these materials have been reported in other publications [11-17]. A wide variety of carbon and silicon carbide fiber reinforced silicon carbide matrix composites $(\mathrm{C} / \mathrm{SiC}$ and $\mathrm{SiC} / \mathrm{SiC})$ have been joined, as shown in Fig. 2. After joining, the microstructure and mechanical properties of joints were characterized at different temperatures. 


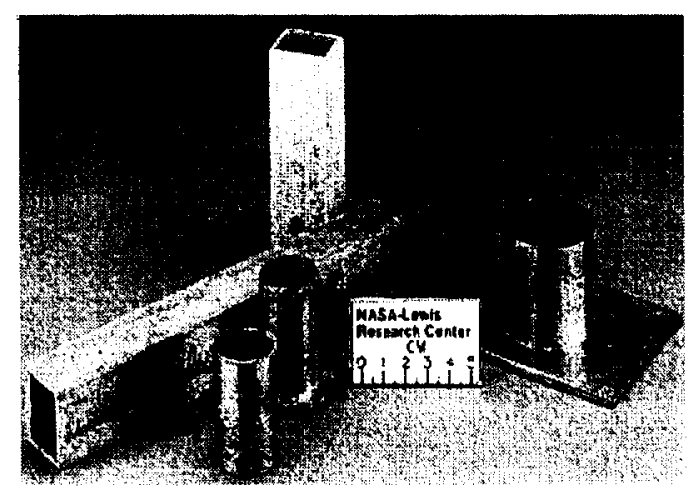

Fig. 2 : Photograph showing components fabricated by joining fiber reinforced silicon carbide matrix composite sub-elements.

The Enhanced SiC/SiC composites used in this study were obtained from Dupont Lanxide Composites, Inc., Newark, DE. These composites were fabricated with plain weave SiC (CG Nicalon) fiber with a thin pyrolytic carbon interface. The SiC matrix was deposited via a chemical vapor infiltration process. For the preparation of specimens for mechanical testing, composite bars of 4 " $\mathrm{x} 1$ " $\times 0.1$ " dimensions were used. As-fabricated surfaces were cleaned in acetone and dried before joining. The composite specimens were aligned to form butt joints.

\section{Characterization}

A scanning electron micrograph of a reaction formed joint-CVI SiC/SiC composite interface is shown in Fig. 3. The joint thickness is about $125-130 \mu \mathrm{m}$. Detailed microstructural examination indicated some residual porosity was present in the joint. There is no visually detectable damage to the fibers. This micrograph also shows a significant amount of porosity in the composite matrix.

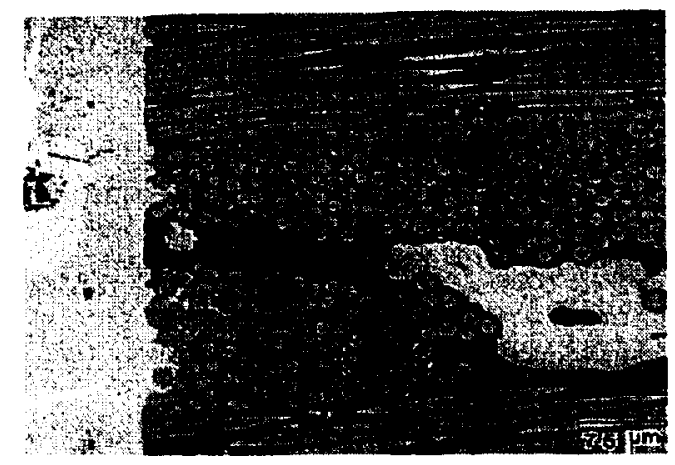

Fig. 3 : Microstructure of reaction formed joint-CVI SiC/SiC interface.

Flexure test specimens were machined from the joined bars, with joints centrally located. Four-point flexural strength testing was carried out using the MIL-STD-1942 (MR) configuration B specimens with $20 \mathrm{~mm}$ inner and $40 \mathrm{~mm}$ outer spans. Flexure tests were conducted at $25^{\circ} \mathrm{C}, 800^{\circ} \mathrm{C}$, and $1200^{\circ} \mathrm{C}$ in air. Four specimens were tested at each temperature. After testing, fracture surfaces were examined by optical and scanning electron microscopy to identify the failure origins.

A summary of flexural strengths of the reaction formed joints in CVI SiC/SiC composite materials is shown in Fig. 4. The average four point flexural strengths of joined specimens at 25,800 , and $1200^{\circ} \mathrm{C}$ were $65 \pm 5$, $66 \pm 9$, and $59 \pm 7 \mathrm{MPa}$, respectively. In the joined $\mathrm{CVI} \mathrm{SiC/SiC}$ materials, fracture initiates in the joint region at the joint-composite interface. Porosity and small amounts of unreacted carbon have been observed in certain areas of the joints. In addition to microstructural inhomogeneities in the joint regions, the mechanical strength of the joints is greatly influenced by delamination and failure at 
the fiber-matrix interface within the composite, which is weak by design. An example of the delamination and interface failure is shown in Figs. 5 (a) and (b), which are the fractographs of joined specimens tested at $800^{\circ} \mathrm{C}$. In these micrographs, one side of the joint pulled away from the weak fiber-matrix interface. This problem can be alleviated by using 3-D architectures or designing the joints in lap, scarf, or other configurations. Efforts are underway to fabricate joints with more homogeneous microstructure and composition, vary the joint configuration and thickness, and evaluate the effect of silicon-refractory metal alloy infiltrants on the microstructure and mechanical properties of joints.

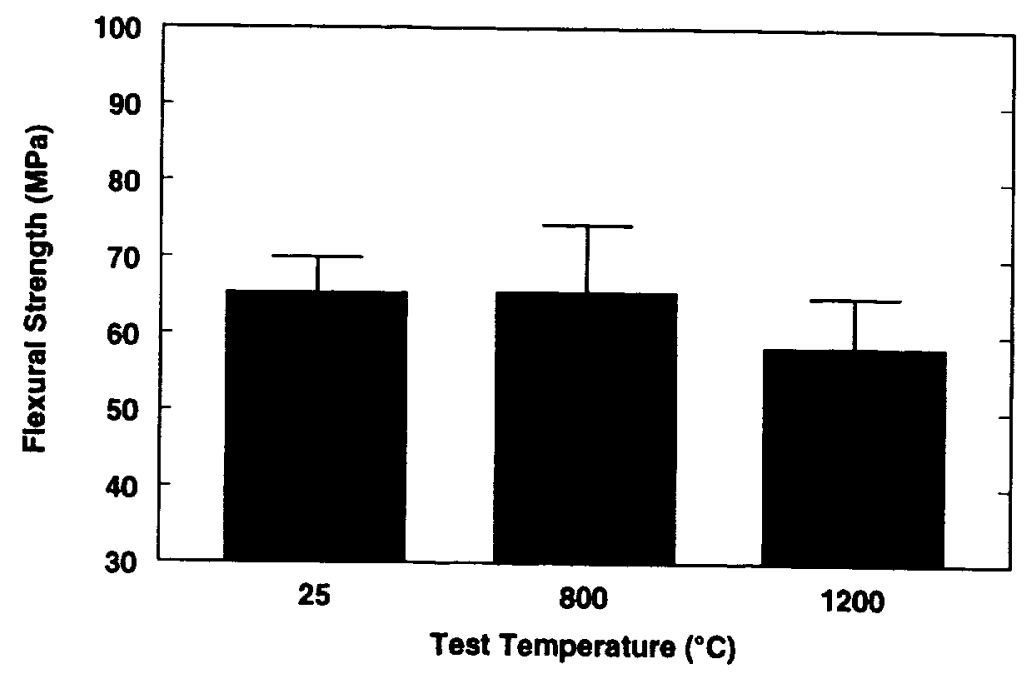

Fig. 4 : Flexural strength of joined $\mathrm{CVI} \mathrm{SiC/SiC} \mathrm{composites} \mathrm{at} \mathrm{low} \mathrm{and} \mathrm{high} \mathrm{temperatures.}$

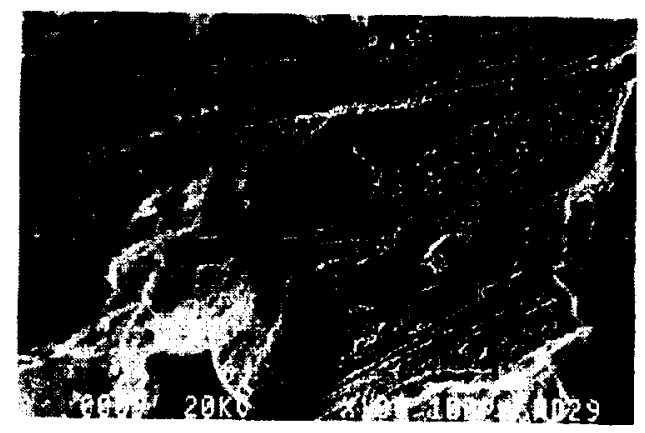

(a)

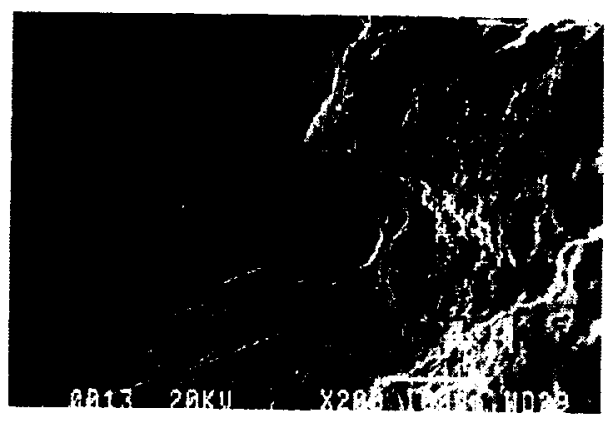

(b)

Fig. 5 (a) and (b) : SEM fractographs of joined CVI SiC/SiC Composites tested at $800{ }^{\circ} \mathrm{C}$. 


\section{Conclusions}

It has been demonstrated that $\mathrm{ARCJoinT}$ approach can be used to join $\mathrm{CVI} \mathrm{SiC/SiC} \mathrm{composites.} \mathrm{These} \mathrm{joints} \mathrm{maintain} \mathrm{their}$ strength up to $1200^{\circ} \mathrm{C}$ in air. The joining technology is affordable and robust, and it can be used for the joining of large and complex shaped components. With further development, it can be adapted to the field repair of silicon carbide-based composite components.

\section{Acknowledgments}

Author would like to thank Mr. R.F. Dacek for his help in the experimental work and to Mr. J.D. Kiser for critically reading the manuscript.

\section{References}

1. Mel M. Schwartz, "Ceramic Joining", ASM International, Materials Park, OH (1990).

2. M.G. Nichols, "Joining of Ceramics", Chapman and Hall, London (1990).

3. R.W. Messler, Jr., "Joining of Advanced Materials", Butterworth-Heinemann, Boston, MA (1993).

4. Mel M. Schwartz, "Joining of Composite Matrix Materials", ASM International, Materials Park, OH (1994)

5. C.R. Bates, M.R. Foley, G.A. Rossi, G.J. Sandberg, and F.J. Wu, Ceramic Bulletin, 69, 3 (1990) 350-356.

6. J.D. Cawley, Ceramic Bulletin, 68, 9 (1989) 1619-1623.

7. R. Larker, A. Nissen, L. Pejryd and B. Loberg, Acta Metall. Mater., 40, 11 (1992) 3129-3139.

8. J.M. Fragomeni and S.K. El-Rahaiby, "Review of Ceramic Joining Technology", Rept. No. 9, Ceramic Information Analysis Center, Purdue University, Indiana (1995).

9. B.H. Rabin and G.A. Moore, Mater. Sci. Engg., A130 (1990) L1-5.

10. W. Krenkel, T. Henke and N. Mason, Key Engineering Materials, 127-131 (1997) 313-320.

11. M. Singh, J.D. Kiser, and S.C. Farmer, Ceram. Engg. and Sci. Proceedings, 18, 3 (1997) 161-166.

12. M. Singh and J.D. Kiser, 'Physics \& Process Modeling and Propulsion R\&T Conference', NASA CP-10193 (1997) 5:1-10.

13. M. Singh, Scripta Materialia, 34, 8 (1997) 1151-1154.

14. M. Singh, Industrial Heating, 9 (1997) 91-93.

15. M. Singh, J. Mater. Sci. Letters, 17, 6 (1998) 459-461.

16. M. Singh, "Microstructure and Mechanical Properties of Reaction Formed Joints in Reaction Bonded Silicon Carbide Ceramics", J. Mater. Sci., (1998) in press.

17. M. Singh, "Affordable, Robust Ceramic Joining Technology (ARCJoinT)", Advanced Materials and Processes, (1998) submitted. 
